University of New Mexico

UNM Digital Repository

Native Health Database Full Text

Health Sciences Center Archives and Special

Collections

1998

\title{
Looking for "a good doctor": a cultural formulation of the treatment of a First Nations woman using western and First Nations method.
}

GV Mohatt

S. Varvin

Follow this and additional works at: https://digitalrepository.unm.edu/nhd

\section{Recommended Citation}

"'Mohatt GV. Varvin S. Looking for "'a good doctor"': a cultural formulation of the treatment of a First Nations woman using western and First Nations method. American Indian and Alaska Native Mental Health Research 8(2), pp 83. 1998'"

This Article is brought to you for free and open access by the Health Sciences Center Archives and Special Collections at UNM Digital Repository. It has been accepted for inclusion in Native Health Database Full Text by an authorized administrator of UNM Digital Repository. For more information, please contact disc@unm.edu. 
Standing Bear, L. (1978). The land of the spotted eagle. Boston: Houghton Mifflin (Original work published 1933)

Stannard, D. (1992). American holocaust: Columbus and the conquest of the New World. New York: Oxford University Press.

The Lakota Times (1990, December). Wounded Knee remembered. The Lakota Times (Special Edition).

Tanner, H. (1982). A history of all the dealings of the United States government with the Sioux. Unpublished manuscript. Prepared for the Black Hills Land with the Sioux. Unpublished manuscript. Prepared for the Black the D'Arcy McNickle Center for the History of the American Indian, Newberry Library, Chicago.

Thornton, R. (1987). American Indian holocaust and survival: A population history since 1492. Norman: University of Oklahoma Press.

Unger, S. (1977). The destruction of American Indian families. New York: Association of American Indian Affairs.

Washburn, W. E. (1988). History of Indian-white relations. Handbook of North American indians, Volume 4. Washington, DC: Smithsonian Institution.

White, R. (1983). The roots of dependency: Subsistence, environment and socia change among the Choctaws, Pawnees, and Navajos. Lincoln: University of Nebraska Press.

Zentner, H. (1963). Factors in the social pathology of North American Indian society. Anthropology, 5(2), 119-130.

\section{Notes}

1. Addressing criticisms of the survivor syndrome, Fogelman (1988a) asserts that, although more empirical studies are needed, the pain and psychological impairment of survivors is not captured by standardized personality tests. Further, differences between children of Holocaust survivors and control groups, supporting the concept of the survivor's-child complex, were found by numerous studies (i.e., Felsen \& Erlich, 1990; Rose \& Garske, 1987; Solomon, Weisenberg, Schwerzwald, \& Mikulincer, 1987).

2. Brave Heart-Jordan. M. Y. H. (1995). Copyright by author: reprints available through the Takini Network, c/o author, University of Denver, Graduate School of SocialWork, 2148 South High Street, Denver, CO 80208.

\section{LOOKING FOR “A GOOD DOCTOR”: A CULTURAL FORMULATION OF THE TREATMENT OF A FIRST NATIONS' WOMAN USING WESTERN AND FIRST NATIONS METHOD}

Gerald V. Mohatt, Ed.D. and Sverre Varvin, M.D.

\begin{abstract}
The following paper utilizes the DSM-IV suggested clinical and cultural formulation to present an example of how First Nations and western treatment methods can work together to treat a First Nation's woman with a serious mental disorder. The formulation provides reflections on cultural elements in the diagnosis and what distinct and common elements are present in the First Nations and western explanatory models for etiology and treatment.
\end{abstract}

Contemporary theorists (LaFromboise \& Rowe, 1983; LaFromboise, Trimble, \& Mohatt, 1990; Lefley \& Pedersen, 1986; Torrey, 1986) question the use of certain forms of psychotherapy, particularly psychoanalytic frameworks, with indigenous people. Some propose that conventional western methods of therapy may actually harm some minority patients. Because western psychotherapies are based on symbolic systems, values, methods, and interactional styles which are culturally inappropriate for Native people, they also increase the likelihood that patients may leave treatment prematurely. As an alternative, Torrey (1986) advocates that Native patients should be referred to traditional healers who perform a culturally based form of psychotherapy.

Other theorists focus more on understanding how culturally-based idioms of help and healing reveal universal features of all healing systems (Frank, 1974; Kleinman, 1988). They articulate how cultures create their own forms of and processes for understanding pathology and administering treatment, which are parallel to western psychotherapy. They consider it appropriate for clients to use their own indigenous systems, which would best serve them. Theyalso recommend that the western professional should 
understand the efficacy of these systems and the culturally based explanatory models for illness and healing. Mohatt (1988) questions a generic recommendation that it is best for therapists to always refer their patients to a medicine man. He sees it as a way for the therapist to avoid difficult personal material and as eschewing the therapist's responsibility to understand the cultural material with the client. He stresses the importance of understanding the idioms of help and explanatory models for healing in order to adapt therapy to the indigenous client. To facilitate such adaptations, LaFromboise, Trimble, and Mohatt (1990) advocate for working closely and in a complementary manner with indigenous healers in training, consultation, and treatment.

Although there appears to be a split between those who consider psychotherapy irrelevant to indigenous people and those who consider it appropriate, much of the literature advocates for cultural adaptation of therapy and complementary work between Native healers and Euro-American practitioners. Duran and Duran (1995) and Devereaux (1951) argue that psychoanalytic or depth approaches, if culturally adapted by a therapist who understands the patient's culture, fit indigenous groups. They and many theorists advocate for a cultural adaptation paradigm that recommends that therapists are trained to understand and become sensitive to cultura dimensions of treatment (Atteneave, 1982; Berg \& Wright-Buckley, 1988 Carter and Helms, 1987; Casas \& Vasquez, 1989; Devereaux, 1951; Erickson 1975; Mohatt, 1988; Trimble, 1976).

Three questions raised by the literature on psychotherapy of American Indian and Alaska Native clients are of importance for the following case presentation:

1. How do First Nations' healing systems conceptualize the illness and healing process?

2. How can indigenous forms of healing be integrated in treatment with psychotherapy?

3. Under which conditions does psychotherapy work effectively for First Nations' clients?

The following case is presented using the DSM-IV recommendation (American Psychiatric Association, 1994) for clinical and cultural formulation in order to provide a unique example of the treatment of a First Nation's woman using both western and First Nations' forms of treatment. The discussion will return to the above three questions and help expand the literature on complementary treatment approaches for Native people.
Clinical History

\section{Patient Identitication}

$H$. was an eighteen-year-old woman from an Ojibwe First Nation, living in central Canada. At the time of the intervention she had been hospitalized for two weeks and was checked out by her family for four days to attend healing ceremonies to be conducted by a visiting Lakota Medicine Man. She lived most recently with her mother, stepfather, and younger sister and half-brother. She periodically lived with her father, with her grandfather, and or with an aunt, thus moving from place to place. At the time of the intervention to be described the family situation was critical for her as her mother and stepfather were discussing splitting up. The mother and stepfather had earlier sought help from Lakota healers for her younger brother when he was born premature with neurological problems. They indicated the belief that the help received had saved their sons life and, therefore, had a positive attitude to the Lakota healers, so they sought similar help for $\mathrm{H}$.

\section{History of Present lilness, Psychiatric History, and Previous Treatment}

At the age of $15, \mathrm{H}$. began to experience problems related to drugs, apparently mainly marijuana abuse. Earlier drug and alcohol experimentation and abuse had occurred, but had not led to problems with others inside or outside the family. The actual extent of her abuse is not known, but it was perceived as a problem by the family and as a cause for her "getting in trouble."

Her first major psychotic breakdown came at age 16 when she worked with young people at a summer-camp. She became agitated, lost sleep, had disorganized thoughts and her behavior was deemed more and more inappropriate. As far as is known, she did not have hallucinations or organized delusions. Her reality testing was, however, impaired and she was hospitalized. She also had suicidal thoughts and behavior, e.g., standing in the middle of a highway hollering and thus in extreme danger of being run over by a car. Her thoughts were, at the time, concerned with First Nations adolescents who were at risk of being damaged by drugs and alcohol and having no safe place to live. Although her thoughts were disorganized, they seemed to reflect accurately both her own situation and that of her peers. She complained about the seeming inability of First Nations' officials to do what was necessary to prevent these problems. She believed that the "system" was corrupted by the "hypocrisy" of the officials who were or had heen abusers of substanres whn were linrarina and corrunt and 
and she was referred to a substance abuse treatment program for sixty days.

In the summer of 1995 at the age of $18, \mathrm{H}$. was again hospitalized. This occurred after she became increasingly depressed following the death Th adolescent cousin who died in a drowning accident. She was also of an adolescent cousin who died in a drowning accident. She was able to attend the funeral and express emotion, but became more and more preoccupied with the safety of her siblings and other young people. During the same time her mother and stepfather began to have increasing marital problems, separated, and were discussing divorce. $H$. expressed great fear that her separated, and were discus volnerable by sister and younger brother would be abandoned and mas using drugs at the such a divorce. The authors do not was dianosed time, however, the family denied this was a problem. She was diagnosed as having bipolar disorder and treated pharmacologically and with milieutreatment. At the time she came for the ceremonies, she was receiving Lithium $450 \mathrm{mg}$ and Chlorpromazine, $150 \mathrm{mg}$. She was, however, strongly critical of the hospital regime, and rejected the thought that her problems critical of the hospital regime, and rejected the thought of mental disorder and were a sign of a mental illness. She felt the "labels" of m the labeling process was a form of condescension which belittled what she considered the truth that she wished people to hear, especially on the part of her parents and public officials. She further experienced the hospital as frightening, being locked up on a ward with very psychotic patients. She felt the Hospital officials denied

the staff had sexually and physically abused her. Hospital officials denit
abuse took place and considered this part of H.'s delusional system.

\section{Social and Developmental History}

H. grew up in a traditional Ojibwe community. Her parents divorced when she was a preteen, after which she lived mostly with her mother. Her mother remarried and she then periodically lived with her mother, stepfather, and siblings who were a full sister and half-brother. She has had a very close relationship with her younger sister. She managed well in school until high school, when she dropped out between her sophomore and junior years, during which time she became increasingly preoccupied and disorganized. The family reported a childhood history of Attention Deficit Hyperactivity Disorder (ADHD) like behavior indicating that $\mathrm{H}$. always had been a bit "scattered," did multiple things at the same time, enjoyed involvement in many activities, and tended to move from one thought to another rapidly. She performed well in intellectual activities and was and is considered very intelligent by friends and family. She had friends but was described as tentative in meeting new people. Many of her friends were those with whom tentative in me .

\section{Family History}

There was no knowledge of psychiatric illness in her family. There is a history of unstable marital relationships and abuse of alcohol among extended family members. $H$. acknowledges great concern about the instability of the family units and their ability as caregivers.

\section{Course and Outcome}

Immediately prior to her second and most recent hospitalization, H.'s parents had separated and were considering divorce. They have subsequently separated. $H$. was considered psychotic upon admission and had to be placed in a locked ward. She received medication and milieutreatment, had sessions with the doctor at the ward but no organized psychotherapy. She had not liked the doctor who had treated her during her first hospitalization so she was very concerned about who would treat her during her most recent hospitalization. Since her previous doctor had resigned, she began to develop a relationship with a new psychiatrist. Although she didn't think he believed her stories about being abused by the staff, she thought he might be able to heip her and expressed a tentative trust in him. Her intake diagnosis was bipolar disorder-manic type.

During the interventions to be described, she manifested a symptom picture that could justify the diagnosis of bipolar disorder of a mixed type. Her history with a previous hospitalization with psychosis and earlier possible attention deficit and increased activity may substantiate this diagnosis, as ADHD like symptoms have been found in the history of adolescents with bipolar disorders. There is, however, controversy connected with diagnosing bipolar disorders in this age-period among others because the symptompicture varies and often is atypical (e.g., mixture of manic and depressive symptoms) (West, 1997). Another consideration that Kleinman (1988) notes is that brief reactive psychosis constitutes a larger portion of acute psychoses in non-westem societies than in the industrialized west. He also indicates that they are often caused by immediate life stressors which have a high degree of cultural salience and they respond well to indigenous healing systems.

\section{Psychodynamic Considerations}

$H$. was a woman in her late teens that had experienced major losses and an unstable home-situation in several periods in her life. She lived in a social environment in which problems related to employment, social stability, and cultural identity were common. This reflected both the actual situations for First Nations' people in Canada but also the history of atrocity, genocide, 
who perceived many of the problems in her family and community. She seemed, however, to have difficulties in distinguishing her problems from those of others. We perceive this as a reflection of her own struggle with identity-formation, including becoming a woman in an unstable social situation that could not give her sufficient support. She seemed to lack a sufficiently that could nith experiences of loss (father and mother's divorce) and the problems of the experiences of loss (father and mother's divorce) and the problems of the tribe-community. It seemed that she felt that the tribe's history mainly offered a victim-identity which arose from her perceiving that First Nations' officials had "sold out", demonstrated many of the problems which they said they wanted to get rid of (e.g., alcohol and substance abuse and the lack of cultural values such as respect of Elders), and failed to take responsibility for protecting the children. She counteracted this by taking on a savior-role for the First Nation youth. In her psychosis this coalesced with her attempts at restoring her own self-fragmentation. It seemed then that the cultural and social (family) setting did not compensate for the turbulence of puberty with its pulls toward fragmentation and return to more impulsive and disorganized behavior and feeling. Loss and separation-anxiety were dominant thernes in her internal world, with her sense of helplessness at times compensated with an omnipotent savior-role, which allowed her to speak the "truth."

\section{Interventions}

$H$. was doctored by a Lakota medicine man during one night through a sweat lodge (oinikage) and a second night of the sweat lodge and a healing ceremony (wapiya lowanpi). The medicine man did not prescribe medicine to assist in the healing but saw the ceremony and sweat lodge as adequate to begin the process of healing. He explained that his friends, the spirits with whom he worked, would strengthen her and that "nothing bad would happen in the future."

The medicine woman present at the ceremony, who was the widow of the medicine man who had doctored the younger sibling, had an alternative perspective and she volunteered to the family to help $\mathrm{H}$. with follow-up. She perspective and she volunteered to the family to help $\mathrm{H}$. with followwhich was affecting her brain and, therefore, needed traditional herbal which was affecting her brain and, the medicine. She explained to $\mathrm{H}$. that medicine was important to facilitate the healing of the body and restore balance and health (wicozani) to her. She explained that each sickness was unique to the person and needed a medicine that fit it. She spoke about the medicine as a relative, which could speak to the body in a way that would help it fight its sickness. She explained that $H$ should speak to her body and explain why she was taking this medicine that $H$. should speak to her body and explain why she was there to help her. She and welcome incested it and welcome it medicine are relatives and the person must assist in establishing the relationship between them in order for health (wicozani) to return. What was critical for wicozani was that the right medicine was found, the correct relative who could speak to the body and to the medicine and establish a healing relationship between them.

Each medicine becomes a unique source of healing for the particular person in this specific context. In this worldview the idiopathic of this person, this problem, and this treatment are salient. During the next four days, she treated $\mathrm{H}$. in the sweat lodges, administered herbal medicine each day for four days, and left medicine with $\mathrm{H}$. to utilize, and had a daily dinner with the family and $H$. after each sweat lodge.

On the second day after the Lakota medicine man's ceremony and the first sweat lodge, $\mathrm{H}$. became acutely psychotic. She re-experienced severe delusions, sensory hallucinations, and agitation. She would not eat or sleep and talked incessantly. Her stepfather sought out the authors and asked for help. We met with the stepfather and $H$. for three hours at a local agency office. Her mind was running at a very rapid pace. She wanted to return to the summer camp immediately. She felt that she had bugs crawling all over her which she kept brushing away with an eagle feather given her by the woman healer.

She performed this act very gently and softly like she was brushing a piece of lint from her sweater. She was vividly reminded of the abuse she felt she had experienced in the hospital. She did not want to eat or sleep, but go immediately to save the children at the camp. She wanted help for herself, a "good doctor" to listen to her. She feared for her sister's safety and wanted her to come and sit with her. She said she had no home to go to, said she would not eat nor sleep, but would remain alert to defend her people, attack and "strike" the enemies in order to save the children. Her speech moved back and forth between these issues. She appeared to be trying to organize her universe, but the points of meaning kept slipping away so she was left without anything to hold onto.

We spent the next three hours in an intense crisis therapy session to bring $\mathrm{H}$. and the stepfather through this crisis moment. We both had to think separately, take our cues from each other, and make our interventions to try to alleviate the crisis. Our psychoanalytic traditions stressed the importance of establishing the subject-object relation, the goals of grounding $H$. in the here and now, re-establishing her relatedness, getting her to eat, to agree to go home, to establish where home was, and to sleep. We both wanted to help her parent learn how to deal with her and what would be needed by her in the next few days and for the long term. We were both leaving the area in the next two days so we had a responsibility to inform him of what options he should consider for her care.

The session had three segments. During the first we worked to 
grounded her and us in the current evolving relationships. We worked very carefully to get her to acknowledge who we were, talking of the recent past e.g., the meeting, the ceremony, and talked with her about her friends and family. In the second segment of the session we worked to get her to eat and drink with us, to have lunch with us. This took over an hour and was contingent on our success in the first segment of anchoring her in relatedness. We succeeded and were able to share a small lunch of peanut butter and jelly sandwiches, juice, and tea. This also mirrored the importance of meals as part of the ending of the ceremony of the previous night.

Finally, in the third segment we finished the session, left her, and made the transition back to her everyday space without a sense of her being abandoned. We had to work to establish the links between her and her stepfather and family, her house, sleep, food, and security. She said she was not going to leave, but we took her step by step through what she would need to do in order to leave the office, the building, how to get into the car, and the one-mile trip home. By this point in the session, her stepfather had watched closely how we work and had joined in with a quiet, patient, and gentle but firm way of communicating with $\mathrm{H}$. She was able to take leave of us. As we stood to leave, she thanked us by giving each of us a pack of cigarettes and a coin as her gift or exchange for the session.

We told the father to return after $\mathrm{H}$. was settled and we would discuss the future with him. They left and we sat and discussed what the options appeared to be from our perspective. The stepfather returned and we discussed the choice of her going back to the hospital or the family working round the clock with her to come through the current crisis and working with the Lakota medicine woman for the next four days. We discussed the pros and cons of both and that they might not be mutually exclusive, since they might want to use the hospital as a possibility if she became much worse. He discussed these with his wife and they decided to continue with the work with the healer, to spend much time with $\mathrm{H}_{\text {., }}$ and not take her to the hospital. The father then tried to call the doctor and the hospital in order to talk to them about the decision. We agreed to speak with the doctors in order to explain the situation, what had happened, and what was planned. We were unable to reach her psychiatrist, but the stepfather would meet with them the next week.

Subsequent to our intervention, $\mathrm{H}$. was treated by the Lakota medicine woman for three more days, became calm, focused, was able to sleep and eat, and decided not to return to the hospital. She did seek out psychotherapy from a variety of sources and was finally able to establish a therapeutic relationship with a psychiatrist at the regional hospital in which she had been a patient. She continued in this treatment for one more year. She also was subsequently doctored once in the following year by the Lakota medicine woman.

\section{Diagnostic Formulation}

The current life-situation of $\mathrm{H}$., with conflicts between parents and losses may have contributed to the outbreak of her illness. Her drug-abuse surely contributed to her instability but may also be seen as an attempt at self-medication because of mood-disorder. There was, however, no information of drug abuse at the time of her current psychosis. Considering the stresses in her life prior to onset, the short duration of her psychotic episode (less than one month), the success of traditional medicine in ameliorating her condition, and the fact that she seemed to return to her prior level of functioning and even improved afterwards with no new psychotic episode during the three years of follow-up and no medication, we think that a more accurate, cautious, and conservative diagnosis would be brief reactive psychosis, with marked stressors. We ruled out schizophrenia because she did not meet the criteria for duration nor social and occupational dysfunction, see Table 1 .

Table 1

Diagnostic Formulation

Axis : $\quad 298.8$ Brief reactive psychosis, with marked stressors.

Differential diagnosis:

296.66 Bipolar I Disorder, Most Recent Episode Mixed, Severe with mood congruent psychotic features.

alternatively;

293.83 Mood Disorder due to Substance-induced With Mixed Features.

Axis II: None.

Axis 1II: None.

Axis IV: Current: Marital difficulties of parent

Fear of loss of parents and death of grandparent.

Residual grief at loss of cousin.

Family instability for siblings.

Past: Divorce of parents.

Family instability.

Perceived insensitivity of local band to needs of adolescents.

Racial discrimination, moderate.

Axis V: $\quad G A F=20$ (at onset)

GAF $=70$ (Highest past year) 
Cultural Formulation

Cultural Identity

Cultural Reference Group(s). $\mathrm{H}$. is an enrolled member of an Ojibwe band in Canada. Both of her parents, stepfather, and extended family are First Nations members.

Language. H. speaks English and some Ojibwe. She has fair rective language abilities in Ojibwe and the language spoken at home had been Ojibwe; however, she speaks English with family members and is most comfortable with English.

Cultural Factors in Development. Her family is traditional on both father and mother's side. They are speakers of the language and $\mathrm{H}$. lived with her grandfather, who was very traditional, while she was growing up. with her grandfather, who was very traditional, whe men. H. experienced how The family respects and utilizes Indian medicine the neurological impairment her younger brother was doctored by and healed of the neuricine man. Subsequent in his infancy through the help of a visiting Lakota medicine man. Subsequent to this, the family involved themselves in healing ceremonicine men or women who had the power to heal in a way that the Lakota healer did. There are, however, members of the community who are seen by the community as medicine men. $\mathrm{H}$ and the family did not consider them able to help $\mathrm{H}$.

Involvement with Culture of Origin. $\mathrm{H}$. has lived on the reservation all of her life. She has lived for brief periods in urban areas of Canada to all of her life. She has lived for brief periods in urban areas of Canada to attend school, to work, or during hosplalizations or the cultural and political early adolescence she has tried to bring attention to thecultural and political problems of her tribe. She took a critical stance towards both her parents and the First Nations officials. Her work at the cultural summer-camp seemed to be motivated by a desire to help young First Nation people, whom she perceived as having serious problems. She seemed, therefore, to be actively perceived as havilure and had an identity as a First Nation member, although involved in her culture and had an identily as a Fir

Involvement with Host Culture. H. participated in ordinary school Involvernent to well in non-Indian settings. She chose to attend activities andseemed to dived in school off the reservation in order to complete high school. She an urban area, although apartment and fell comfortable with the anonymily of an urbane rather she reported that she felt lonely and isolated. She chose to live alone rather than with others while in the urban context and did well in completing her cherestion is quite schooling. Movement continued over many contemporary generations.

\section{Cultural Explanations of the IIIness}

Predominant Idioms of Distress and Local IIIness Categories. The symptoms presented by $H$. are recognized in the community as a serious problem. The most widely used explanation is substance abuse from over using cannabis or alcohol; the community tends to look to this cause for much deviant adolescent behavior.

Meaning and Severity of Symptoms in Relation to Cultural Norms. People within the community acknowledged that all adolescents have adjustment problems and the community is sensitive to the problems youth have with schooling and the dominant Euro-Canadian attitudes toward First Nations' people. However, H.'s behavior was considered atypical and serious enough that she needed professional help and hospitalization. To protest politically the action of the band, First Nations' members frequently argue with the Council and its leaders. However, H.'s behavior varied in degree and methods. She would appear at any time demanding to be heard. She would disrupt public and private meetings.

Her fears of harm coming to the children at the camp was viewed as paradoxically antithetical to both her goals and the goals of the camp and as not based in reality. Finally, her public behavior of standing in the road and hollering was seen as putting her and others in danger and that she suffered from uncommon and severe problems.

Perceived Causes and Explanatory Models. Such uncommon behavior made the local people look beyond the conventional explanations of alcohol and substance abuse to spiritual causes. Most predominant of these was the "bear walk" which is caused when a person with power wishes bad on another and can come to the other in the form of a bear and cause serious harm. Although $\mathrm{H}$. did not dream of bears or speak of such experiences, there was concern that someone might be trying to harm her. When suicides have occurred in the community, this type of bad medicine was seen as explanation of the causation. Concern existed on the part of the family that such bad medicine might be or could become involved. If this were the case, they needed very powerful medicine to counteract it. The family also wondered if $H$. had a mental illness and whether it was amenable to doctoring by a medicine man. Given the periodic nature of involvement with traditional healers and the limited family socialization in traditional worldviews about such illnesses, the family did not have a clear traditional explanatory model for the problem.

$H$. and her family live in a bicultural world. Western medicine has strong influence in this area, and is frequently used when people get ill. $H$. and her family decided that western medicine was worthwhile and should be used. The family and community accepted the possibility of biological causes for the problem and the potential for western medicine to help. However. 
problem could have a spiritual cause, that western medicine was not producing a cure, and their satisfaction with the traditional doctoring of their youngest child, the family with H.'s consent turned to Lakota healing.

In the First Nation's context, spirituality and the power of rituals and healing-ceremonies is the important approach for disease. The indigenous conceptualization of her illness saw the problem not only lodged in her, but as reflecting problems in her family, her peer-group, and her tribe, who were all in crisis. A biological conception was also presented by one of the Lakota healers, but seen as a consequence of trauma. The body (ta'chan) was one part of a triangle together with the person's spirit (nagi) and the world of relatives, the spirits and other people (mitakuye oyasin), all of which could work together in order for health (wicozani) to be re-established. Wicozani includes rapid symptom relief and the reestablishing of relationship with others, particularly kinship relationships. The Lakota healer stressed to the family that it was necessary for all of the relatives to be present and to achieve a sense of a singleness of desire among every one at the ceremony in order for the patient to achieve health. The singleness of desire (wowacin wanjila) involved everyone being there for the healing of $\mathrm{H}$ rather than to get something for themselves or ask for healing for themselves. This wowacin wanjila would create a context in which the power of the spirits could touch $\mathrm{H}$. in a way that she would feel safe in relationship to others. Additionally, $\mathrm{H}$. was seen as having a weakening of desire and will (wowacin hunkesni) which was consequent on the fractures within her family and community. The ceremony was seen as strengthening the will and assisting $\mathrm{H}$. in regaining a strength of desire and will (wowacin tanka).

Restoration of the health of the body is one critical dimension. However, equally important to cure is to restore relatedness within the family. The salient elements in the indigenous conception of illness were thus problems of the relationship between the spirit and the body and disruption in human relatedness. Her symptoms were, at this level, then seen mainly as a consequence of her struggle with such problems, not as a cause of an inherent illness.

Help Seeking Experiences and Plans. As noted earlier, H. was on leave from the hospital. She did not plan to go back to the hospital nor did she want to take western medicine. However, she was insistent that she needed a "good doctor," defined as one who will listen and talk to her. H. had experienced this type of doctor in her substance abuse treatment, but since she could not retum there she wanted to find a counselor or psychotherapist that would listen to her and not give her medications.

\section{Cultural Factors Related to Psychosocial Environment and Levels of} Functioning

Social Stressors. $H$. had been unemployed because permanent employment was dependent on graduating from high school. She had been able only to find seasonal and temporary work. However, she entered a special program to finish high school after which she was hired by a local employer. She continued, however, to be unsure of her career goals and moved again to an urban area. The level of alcohol and drug abuse among peers was also perceived as a stressor.

Social Supports. The ceremonies in which $\mathrm{H}$. was doctored were attended by a large number of relatives and friends. She received strong words of encouragement and prayers from those who attended. They shared personal narratives and committed themselves to help her. Family members continued to support her during follow up treatments, which included daily dinners in the evenings following the sweat lodge with friends and extended family members. She continued to receive active encouragement to return to the community and work, and was weicomed back and supported with a job.

Levels of Functioning and Disability. As a consequence of the ceremonies, social support, and individual psychotherapy, $H$. was able to weather a number of challenges. She began to abuse substances, primarily alcohol, but was encouraged to stop by relatives and did so. She also became depressed and discouraged, wondering if she would "make it." However, she did not become actively psychotic and did not have to be rehospitalized. She kept in contact with both the Lakota medicine woman, her therapist, and wrote the authors twice a year. Her letters contained pain and hope but she said that she felt strong enough to weather these storms.

$H$. has significantly improved in the past three years, maintaining a job for over a year and completing high school. However, it is expected that she will continue to struggle, but she has strong social support and increasing ego strength to continue to improve.

\section{Cultural Elements of the Clinician-Patlent Relationship}

European or Euro-Canadian therapists varied in their level of knowledge of First Nation's culture. The primary therapist had little knowledge of the healing systems that $H$. was using, but he was respectful and cooperative. He wanted her to utilize both therapy and medications, but she refused and asked for a "good doctor who would listen." To his credit, he agreed and worked within a treatment modality which included traditional healing rituals. There was no contact between the doctor and either the Lakota medicine man or medicine woman. The Lakota medicine man had t:L1_ 1....... 
The medicine woman had extensive experience on the reserve and was familiar with both the Ojibwe culture and the particular family context. She was highly respected because of both her own performance and her status as the widow of a medicine man who had provided extensive help to many people on the reservation.

The crisis intervention session was well received by $\mathrm{H}$. One therapist had extensive experience with First Nations' people and with H.'s community. The other therapist was a psychoanalyst with extensive cross-cultural experience with traumatized war refugees and individuals with psychosis. During the crisis intervention, the pace and style of speaking included low volubility, long pauses, much reassurance, and an attention to the here and now. The father was included. The interactional styles and other elements described in the intervention mirrored the rules for social interaction in the community. Following the crisis intervention, there were discussions between the therapists and the medicine woman. Follow up with $\mathrm{H}$., her family, and the medicine woman by one of the crisis intervention therapists to assist in arranging for treatment options was important because of the cultural importance of continuity of relationship and helping. Once a psychotherapist was identified, the family and $\mathrm{H}$. worked primarily with him and the medicine woman to gain needed services.

\section{Overall Cultural Assessment}

The case of $\mathrm{H}$. is a complex presentation of how a First Nation's woman who experienced significant psychotic symptoms was understood and treated by both.western professionals and traditional healers. The clinical and cultural formulations delineate two views of H.'s problem.

The two cultures vary in the goal of treatment (cure or management) and the centality of spirituality in First Nations' models for healing. However, other aspects of the explanatory models for treatment are not inherently contradictory. It may well appear to the western practitioners that $\mathrm{H}$. will develop a bipolar, chronic disorder. The complexity of her culture and her life situation, calls for extreme caution, especially when the person is in a turbulent adolescent developmental phase. One crucial treatment problem for western practitioners is whether Lithium treatment is justified or not. The combination of biological, psychological, and social approaches is a solid part of both Lakota and western tradition. $\mathrm{H}$. refused the biological part of western medicine yet embraced the First Nations use of traditional herbal medicine. The western practitioners knowledge of and respect for the biological treatments of First Nations' healers is important. Attention to the best traditions of western practice and First Nation's worldview insists that we insure that the choice of the patient is central in their treatment. Whether we conceptualize this as facilitating collaborative empiricism in a cognitive there are common bonds with the concern of First Nations' people that healing comes out of freedom of choice.

In H.'s case a key question then is how can a patient make an informed choice when the person is severely disorganized and acutely psychotic. Part of the role of medications, crisis intervention, and hospitalization in a western framework reestablishes the needed connections to reality. It is also a goal of the sweat lodges, the dinners following them, and the use of herbal medicine to activate a new relationship between spirit and body. These each may calm the patient and ground them in human relationships, so they can make an informed choice about their treatment. Although significant differences existed in the western and First Nations approaches, enough common ground existed for complementary treatment to occur and for $\mathrm{H}$. to find each system helpful.

$H$. found the ceremonies helpful to reestablish bonds at an emotional level with others. The help that she received strengthened her own sense of identity as a First Nation's person and gave her a sense of respect for her community. At the same time, the ceremonies strengthened her resolve to find a western doctor who could help her on her own terms. Following the ceremonies, $H$. became more persistent and uncompromising in this and convinced the hospital psychiatrist to do psychotherapy with her. She committed herself to continued contact with the medicine woman, feeling that she would be helped by her ceremonies. $\mathrm{H}$. emerged from the experience of these complementary treatments with a greater sense of cultural identity and a renewed sense of her competence to complete her education and work. The activation of social support networks helped her to realize she had a home and a community to which she could return and which was no longer seen as dangerous and threatening, but as potentially nurturing. She additionally came to a growing realization that spiritual help was available.

Family members spoke about how the ceremonies helped them realize how they could help. In a very real sense the ceremonies treated the family and community by encouraging them to come to the support of $\mathrm{H}$. and showing them the power they had to help. The family kept in contact with one of the crisis intervention therapists who helped them look for resources and encouraged them in pursuing both traditional medicine and psychotherapy. The step-father experienced three hours of crisis intervention and through the modeling of the therapists he said that he learned something about how to react to acute psychotic behavior, i.e., how to be calm in the face of psychotic material and how to assist the person in coping and reconnecting to the here and now. The interventions served to increase the skill and competence of the family and the confidence that they could help H.

Subsequent developments have shown that $H$. has significant work to do to maintain her health with a potentially significant challenge related to 
however, that she is gradually improving. The progress in gaining relief from symptoms through ceremonies, and her choice of work with traditional arts and crafts enhanced her ethnic identity. The level of symptom relief, its continuity, and her response to traditional healing reinforces our opinion that she has emerged from a brief adolescent reactive psychosis rather than a mood disorder. She possesses increased cultural identity and enhanced ego strength to develop an adult role and identity. The medicine woman continues also to be optimistic about H.'s recovery but believes she will continue to struggle to avoid substance abuse.

Returning to the questions in the introduction, the treatment of $\mathrm{H}$. suggests that psychotherapy can assist the First Nations' client if it serves her/his goals and is done in a way that fits the social interactional cultural rules and, in this instance, the cultural norm of family involvement. Second, therapy can serve as a complement to indigenous healing provided that the client is motivated to utilize both systems and the principal practitioners are willing to work in a complementary manner. In the case of $H$. she refused psychotropic medication but accepted traditional herbal medicine provided by the Lakota healer. If the healer had instructed her not to use western medicines a potential conflict would have occurred, which does happen at times when the two systems interact. At other times western practitioners advise their patients to not use local healers in place of their treatment. However, in this case these types of conflicts did not occur.

Both systems can complement each other, but there are significant areas of difference that can cause conflict. Goals and explanatory models for etiology and treatment vary. What appears critical in this instance is that the client directed how these systems would serve her and each system helped meet particular needs of the client. The medicine woman focused on the biological, spiritual, and social-interpersonal levels. The crisis intervention contributed to the family's competence and rapid symptom relief. The longer-term psychotherapy allowed a place for $\mathrm{H}$. to speak and be heard by a good doctor. All of the systems contributed to restoring H.'s ability to relate to others and a positive grounding in human community. H.'s case provides an instructive example of how the two systems can assist in the restoration of health (wicozani) and how adaptation of therapy to the First Nations' client facilitates treatment and outcome.

\section{Afterword}

It appears that $\mathrm{H}$. found many good doctors, each providing help in her struggle to achieve and maintain health. She convinced the psychiatrist that was seeing her in the hospital to be her therapist and she returned to therapy for a period of a year. She also continued to seek social support and advice from the authors by sending them letters with updates on her and saw her whenever she returned to the reservation. The healer doctored her until she was well enough to no longer need herbal medicine and ceremonial assistance. This came when $\mathrm{H}$. was strong enough to cope independently and had significant symptom relief. The medicine woman still hears from $\mathrm{H}$. frequently, and is prepared to return to help her if she asks. $H$., therefore, continues to have available a set of complementary treatments involving both western psychotherapy and traditional healing.

- Gerald V Mohatt, Ed D University of Alaska, Fairbanks Department of Psychology

P.O. Box 756480

Fairbanks, AK 99775-6480

\section{References}

American Psychiatric Association. (1994). Diagnostic Statistical Manual of Mental Disorders-IV. Washington, DC: American Psychiatric Association.

Atteneave, C. (1982). American Indians and Alaska Native families: Emigrants in their own homelands. In M. McGoldrick, J. K. Perarce, \& J. Giordana (Eds.), Ethnicity and family therapy (pp. 55-83). New York: Guilford Press.

Berg, J.H., \& Wright-Buckley, C. (1988). Effects of racial similarity and interviewer intimacy in a peer counseling analogue. Journal of Counseling Psychology, $38,440-445$.

Carter, R. T., \& Helms, J. E. (1987). The relationship of Black value-orientation to racial identity attitudes. Measurement and Evaluation in Counseling and Development, 19, 185-195.

Casas, J. M., \& Vasquez, J.T. (1989): Counseling the Hispanic client. A theoretical and applied perspective. In P. B. Pedersen, J. G. Draguns, W. L. Lonner, \& J. E. Trimble (Eds.), Counseling across cultures (3rd ed., pp. 177-204). Honolulu: University of Hawail Press.

Devereaux, G. (1951). Three technical problems in psychotherapy of a plains Indian woman. American Journal of Psychotherapy, 5, 411-422.

Duran, E., \& Duran, B. (1995). Native American postcolonial psychology. Albany, NY: SUNY Press.

Erickson, F. (1975). Gatekeeping and the melting pot: Interaction in counseling encounters. Harvard Educational Review, 45(1), 44-70.

Frank, J. D. (1974). Persuasion and healing: A comparative study of psychotherapy (2nd ed.). Baltimore, MD: Johns Hopkins Press. 
LaFromboise, T., \& Rowe, W. (1983). Skills training for bicultural competence: Rationale and applications. Journal of Counseling Psychology, 30, 589595.

LaFromboise, T. D., Trimble, J. E., \& Mohatt, G. V. (1990). Counseling intervention and American Indian tradition: An integrative approach. The Counseling Psychologist, 18(4), 628-654.

Lefley, H. M., \& Pedersen, P. D. (Eds.) (1986). Cross-cultural training for mental health professionals. Springfield, IL: Charles C. Thomas. -

Mohatt, G. V. (1988). Psychological method and spiritual power in cross-cultural psychotherapy. Journal of Contemplative Psychotherapy, 5, 85-115.

Torrey, E. F. (1986). Witchdoctors and psychiatrists: The common routes of psychotherapy and its future. New York: Perennial Library.

Trimble, J. E. (1976). Value differences among American Indians. Concerns or the concerned counselor. In P. Pedersen, W. J. Lonner, \& J. G., Draguns (Eds.), Counseling across cultures (pp. 65-81). Honolulu: University of Hawaii Press.

West, S. A. (1997). Adolescent mania and bipolar disorder. Medscape Mental Health, 2(10), 1-9.

\section{Notes}

1. First Nations is the way in which Canadian Indians refer to themselves in contemporary society.

2. For H. First Nations officials included council members, the chief, and some of the administrators. 
American Indian and Alaska Native Mental Health Research

The Journal of the National Center Volume 8, Number 2, 1998

Teacher, Parent, and Youth Report of Problem Behaviors Among Rural American Indian and Caucasian Adolescents Philip A. Fisher, Ph.D., Jan G. Bacon, Ph.D., and Michael Storck, M.D.

Boarding and Public Schools: Navajo Educational Attainment, Conduct Disorder, and Alcohol Dependency

Eric Henderson, Ph.D., J.D., Stephen J. Kunitz, Ph.D., M.D., K. Ruben Gabriel, Ph.D., Aaron McCright, B.A., and Jerrold E. Levy, Ph.D.

Factors Influencing the Pursuit of Educational Opportunities in American Indian Students

Chris L. Fore, Ph.D. and John M. Chaney, Ph.D.

The American Indian Holocaust: Healing Historical Unresolved Grief

Maria Yellow Horse Brave Heart, Ph.D.

and Lemyra M. DeBruyn, Ph.D.

Looking For "A Good Doctor": A Cultural Formulation of the Treatment of a First Nations Woman Using Western and First Nations Method

Gerald V. Mohatt, Ed.D. and Sverre Varvin, M.D.
TEACHER, PARENT, ANDYOUTH REPORT OF PROBLEM BEHAVIORS AMONG RURAL AMERICAN INDIAN AND CAUCASIAN ADOLESCENTS

Philip A. Fisher, Ph.D., Jan G. Bacon, Ph.D., and Michael Storck, M.D.

Abstract: Previous research on the mental health status of American Indian youth has documented rates of pathology that are higher than the rates for Caucasian youth. However, much of this previous research has compared rural American Indians to uman Caucasians. The present study is a comparison of American Indian and Caucasian youth living on or near a rural reservation. Results suggest that although American Indian youth have higher lovels than Caucasian youth of certain problem behaviors, group differences are much leiss general and pronounced than previous research has documented. Analyses also revealed teachers' perceptions of youth were in some cases quite different than parents' perceptions of youth and youth's perceptions of themselves.

According to the most recent census, there are over two million American Indian people living in the United States (U.S. Bureau of the Census, 1996). Of these, estimates are that $22 \%$ reside on tribal reservations and trust lands, and that between ten and forty percent more live in towns and cities very close to reservations (Beals, Keane, \& Manson, in press; Norton \& Manson, 1996). There are over five-hundred American Indian tribes and Alaska Native villages, many of which are federally recognized and others which are seeking re-recognition as sovereign nations (U.S. Department of Commerce Census Bureau, 1993). Although there exists a broad diversity of cultural organization among the tribes, American Indian peoples share signiticant cultural values and some important demographic trends and health concerns. One of the more notable demographic characteristics of the American Indian population is its relative youth: $39 \%$ of the American.Indian population is under age 20 , in contrast with $29 \%$ among the United States 